\title{
Robert McRuer; Anna Mollow (orgs.) (2012), Sex and Disability
}

Ana Lúcia Santos

\section{OpenEdition}

\section{Journals}

Edição electrónica

URL: http://journals.openedition.org/rccs/4976

DOI: $10.4000 /$ rccs. 4976

ISSN: $2182-7435$

Editora

Centro de Estudos Sociais da Universidade de Coimbra

\section{Edição impressa}

Data de publição: 1 junho 2012

Paginação: 155-157

ISSN: 0254-1106

\section{Refêrencia eletrónica}

Ana Lúcia Santos, «Robert McRuer; Anna Mollow (orgs.) (2012), Sex and Disability », Revista Crítica de Ciências Sociais [Online], 97 | 2012, posto online no dia 19 abril 2013, consultado o 22 setembro 2020 URL : http://journals.openedition.org/rccs/4976 ; DOI : https://doi.org/10.4000/rccs.4976 


\section{Recensões}

\section{Robert McRuer; Anna Mollow (orgs.) (2012), Sex and Disability. London: Duke University Press, 418 pp.}

Raros são os textos, tanto no campo da sexualidade como no campo dos estudos da deficiência, que tratam das práticas sexuais na deficiência. Conscientes desse défice, Robert McRuer e Anna Mollow editaram recentemente a primeira antologia que relaciona sexo e deficiência. Esta coletânea reúne dezassete capítulos que propõem desvelar a sexualidade neste âmbito. Os capítulos dispõem-se por cinco secções que tratam do acesso, das histórias, dos espaços, das vidas e dos desejos.

A capa do livro é uma janela aberta ao que se vai passar a seguir: um soutien cobre dois pictogramas vermelhos de cadeirantes, voltados um para o outro; um esqueleto vestido com uns boxers de onde, pela braguilha, sai uma muleta axilar; e um título prometedor e aparentemente contraditório, Sex and Disability.

Do sexo à deficiência, do desejo ao fétiche, esta obra perturba o imaginário popular de categorias até agora amplamente reservadas, imaginário no qual perdura a inextricável ligação entre sexo e corpo 'são' - apenas o “corpo são em mente sã” é dotado de sex appeal, capaz de provocar desejo e de fazer sexo. Os corpos deficientes são tendencialmente considerados feios, incapacitados, assexuados ou hipersexuados, e contrariamente aos corpos sãos, permanecem fora do controle das próprias pessoas que os habitam. Ao longo das páginas confundem-se os termos queer, crip e deficiente. De certa forma, McRuer dá aqui continuidade ao seu projeto da teoria crip (Crip Theory, NYU Press, 2006) que relaciona deficiência e queerness.
Quando pensamos na relação entre os conceitos "acesso" e "deficiência”, a tendência é para um enfoque nas barreiras físicas ou atitudinais que as pessoas deficientes enfrentam no acesso à vida social e profissional - ou seja, a vida pública. Contudo, num livro que trata de sexo e deficiência, quando se fala em acesso trata-se de uma outra dimensão: o acesso às experiências sexuais, sejam elas partilhadas ou não. $\mathrm{O}$ acesso à sexualidade pressupõe antes de mais o acesso ao próprio corpo. Partindo deste pressuposto, o livro começa pertinentemente por tratar daquilo que que Kenneth Plummer designa por "cidadania íntima”. De acordo com o sociólogo, a cidadania íntima diz respeito ao poder de controlo sobre o próprio corpo, os sentimentos e as relações, assim como ao acesso ao exterior e às escolhas. É um conceito que relaciona esfera privada com esfera pública, particularmente útil à sexualidade deficiente uma vez que esta transgride a fronteira entre aquelas duas esferas. Na primeira secção, "Access”, o primeiro capítulo, "A Sexual Culture for Disabled People”, de Tobin Siebers, contrapõe as noções de "vida sexual" e de "cultura sexual" para lembrar a importância da sexualidade na vida quotidiana, que extravasa o privado. $\mathrm{O}$ autor adverte para a necessidade de reconhecer a sexualidade de pessoas deficientes enquanto sexualidade minoritária e recorre à ativista e escritora Anne Finger para demonstrar que a opressão sexual é a mais profunda das opressões que as pessoas deficientes sofrem. Este contributo é particularmente importante porque encara as dificuldades 
de acesso a locais de sexo por que passam as pessoas deficientes, levando-nos a pensar de que forma o capacitismo - ideologia sobre o elogio da capacidade, do corpo 'capaz' - molda o nosso pensar acerca do sexo. Por outro lado, celebra a sexualidade das pessoas deficientes que, em virtude da sua diferente geografia sexual, podem fazer sexo em público sem que ninguém se aperceba. Siebers dialoga ainda com as questões da reprodução, da eugenia e dos custos do direito à privacidade. Ao deslocar o sexo na deficiência para fora da cama e do quarto, para locais improváveis, subverte-se a tradicional ideia de tragédia e assexualidade na deficiência. O sexo está para além das zonas eróticas. Sexo é mais do que uma relação genital. A deficiência desafia as conceções de identidade sexual que conhecemos e desmantela a identidade de assexuado que a cultura lhe imprime. De resto, toda esta secção se desenrola em torno de um novo entendimento do conceito de acessibilidade - relacionado com a intimidade sexual e apela a uma mudança cultural. Alerta-nos para a importância de se criarem novos modos de acesso ao sexo e novos modos de fazer sexo.

Segundo Mollow e Robert (p. 7), "A identidade deficiente [...] nunca é um simples facto natural; é antes feita e refeita em circunstâncias históricas e por agentes históricos”. Daí a necessidade de seguir em frente com uma série de artigos que dão conta da história, não da deficiência ou dos movimentos da deficiência, mas da história individual, de uma determinada história num determinado contexto, uma história que perturba a tradição dos trabalhos académicos. A secção "Histories" trata de histórias fictícias e reais, desde Billy Ray Johnson, um afro-americano com deficiência mental que foi brutalmente espancado por quatro jovens brancos, ao protagonista deficiente do bestseller vitoriano The History of Sir Richard Calmandy, ou aos homens grávidos, protagonistas de romances ou da vida real como Thomas Beatie, transexual que desde a sua transição já concebeu quatro crianças.

Tão importante quanto o acesso aos locais de sexo são os espaços geográficos e discursivos de materialização do sexo e da deficiência. No capítulo "Leading with Your Head: On the Borders of Disability, Sexuality and the Nation" da secção "Spaces", Markotic e McRuer analisam o discurso de atletas no documentário Murderball (2005) e desvelam o seu sentido ora subversivo, ora hegemónico, patriarcal e heteronormativo. Desde o terceiro género - fa'afafine - reconhecido na Polinésia, passando pela intersexualidade ou pela experiência do VIH contado na primeira pessoa, esta secção, para além da atenção dedicada aos espaços do sexo e suas limitações, é uma crítica à privatização da sexualidade, incluindo aquela que é veiculada pela academia.

$\mathrm{Na}$ secção "Lives", no decurso de várias autobiografias saem do silêncio vozes de pessoas deficientes que falam das suas experiências com a sexualidade, ilustrando pontos de cruzamento entre a vida destas pessoas e das pessoas queer, na medida em que ambas são alvo de disciplina e impelidas a agir com "normalidade".

Os últimos capítulos do livro constituem igualmente marcos teóricos e políticos significativos. Se em toda a obra somos confrontadas/os com os nossos próprios preconceitos, em "Desire and Disgust", de Alison Kafer, e em "Hearing Aid Lovers, Pretenders, and Deaf Wannabes", de Kristen Harmon, a ideologia capacitista do sexo, da identidade sexual e do desejo são radicalmente desafiadas. Devotees, pretenders, wannabes: estas são as personagens fetichistas que perturbam os/as mais sensíveis. Devotee - pessoa não deficiente que se sente sexualmente atraída por pessoas 
com deficiências, especialmente de mobilidade, como amputações; pretender - pessoa não deficiente que se comporta como se tivesse deficiências (uso de cadeira de rodas, aparelho ortodôntico, etc.), em privado e/ou em público; wannabe - pessoa que deseja tornar-se deficiente, podendo, inclusive, mutilar partes do corpo. Falar destes tópicos é um dos vários caminhos para contrariar a des-sexualização das pessoas com deficiência. O desejo por um corpo fora da norma levanta questões acerca da corporalidade, da autenticidade, dos aspetos sociopolíticos da identidade e das deficiências.

Este é um livro que se revela de grande importância não só para os estudos da deficiência como também para os estudos queer e estudos sobre sexualidade devido à intersecionalidade dos temas e ao arrojo reflexivo com que estes são tratados. Não obstante, esta utilidade não se limita ao contexto académico. Se estes temas permanecem subestudados e acantonados na academia, $\mathrm{o}$ mesmo se passa na sociedade em geral, o que reforça a relevância desta obra para públicos diversos, com a ressalva de que é provocante e desafiadora, capaz de surpreender até as/os mais insurgentes. Seria impossível reunir em 400 páginas todo o reportório de vivências em torno da sexualidade na deficiência, mas este é sem dúvida um contributo incontornável para quem se interessa pelo tema, abrindo ainda pistas preciosas face ao que está por fazer neste campo.

Ana Lúcia Fonseca Santos

\section{Rosanna Barros (2012), Subsídios breves para o debate de princípios e valores na formação política do(a) educador(a) social. Lisboa: Chiado Editora. $245 \mathrm{pp}$.}

O livro Subsídios breves para o debate de princípios e valores na formação politica do(a) educador(a) social, da autoria de Rosanna Barros, prefaciado pelo Prof. Doutor Almeirindo Afonso, encerra uma trilogia cujos dois primeiros livros foram publicados em 2011: A criação do reconbecimento de adquiridos experienciais (RVCC) em Portugal: uma etnografia crítica em educação de adultos e Genealogia dos conceitos em educação de adultos: da educação permanente à aprendizagem ao longo da vida. Trata-se de obras que, embora autónomas, se complementam e se enriquecem mutuamente, provocando e ampliando a reflexão crítica e o debate sobre questões fundamentais no campo da educação, da formação, da participação e do exercício de uma cidadania ativa, interventiva, emancipadora, transformadora.

Ao longo da obra, a autora procura "clarificar conceitos e tecer aproximações teóricas a certos aspetos que estão inscritos na base da ciência política" (p.19) que considera fundamentais na formação crítica e problematizadora dos/as estudantes e profissionais de educação social.

O objetivo deste livro é, conforme expresso na sua introdução, o de contribuir para atenuar algumas dificuldades que a autora tem testemunhado "existirem no quotidiano dos(as) jovens estudantes para encontrarem, na literatura de língua portuguesa, [...] balizas de trabalho e mapas de referência [...] que enformem uma orientação material para o estudo, que sirva, assim, para o(a) estudante desta área de banda larga, a partir daqui, escolher obras seminais claramente identificadas nas temáticas especializadas e nas problemáticas de fundo associadas quer a uma introdução à ciência política por parte de um educador, quer a uma educação engajada que ambicione contribuir para 
desencadear, em contexto, a transformação social” (p. 20-21).

A obra está estruturada em duas partes que, embora distintas, se complementam. Considerando a autora que "é partindo da consciência crítica sobre a complexidade ideológica de base claramente patente na história do pensamento político ocidental moderno, que se poderá extrair, reconstruir e propor modelos interpretativos da realidade sócio-política que contribuam de maneira original para aumentar o engajamento do(a) educador(a) social na prossecução de projectos que contribuam para a transformação social desde o seu campo de actuação" (p. 213), percebe-se a opção de a primeira parte do livro ser dedicada a uma abordagem sobre as ideologias políticas modernas e sobre teorias do Estado, na qual são organizados conceitos e teorias. Após circunscrita conceptualmente a evolução moderna do sentido atribuído à noção de ideologia, são apresentadas as diversas ideologias políticas quanto ao entendimento público conferido ao vasto tema do poder político.

Centrando-se em três eixos gerais - nas origens determinantes, nas características fundamentais em termos de pensamento político e social e nas escolas e correntes de pensamento principais que estabelecem entre si um diálogo interno, pela sua pertinência -, são detalhadamente analisadas as ideologias políticas modernas: o liberalismo, o conservadorismo, o socialismo, o anarquismo, o fascismo, o feminismo e o ecologismo e as vinte e seis escolas de pensamento que as mesmas propõem, e assim esplanadas as diversas conceções do mundo e da organização da vida em sociedade por si propostas.

Ainda na primeira parte são apresentadas as principais linhas de controvérsia existentes quanto à organização, ao papel e sentido a atribuir ao poder público formalmente entendido como Estado, sendo abordadas as cinco principais teorias: a teoria absolutista, a teoria constitucional, a teoria ética, a teoria clássica e a teoria pluralista.

Ao longo da segunda parte do livro, intitulada "Estado e sociedade na modernidade ocidental: um debate ideológico e de princípios incontornável para uma educação transformadora", a autora apresenta questionamentos essenciais que, face ao panorama da relação moderna entre o Estado e a sociedade, induzem à reflexão sobre a postura crítica que o/a educador/a social deve assumir, na conjuntura hegemónica e claramente tecnicista vivenciada neste início de século.

São sistematizados alguns dos fundamentos do pensamento desenvolvido em torno dos fenómenos políticos e da questão do governo, deixando a autora, de forma expressa, a intenção de enquadrar o "contexto de emergência dos Estados modernos e das problemáticas de fundo inerentes à crise estrutural dos Estados Capitalistas democráticos" (p. 22). Apresentando os conceitos de Estado, de crise, de capitalismo, de democracia, deixa contributos para uma mais informada compreensão crítica sobre o processo de construção e desconstrução do Estado-Providência e o emergir do Estado Neoliberal, afirmando a imprescindibilidade de reclamar para os nossos dias a necessidade de construir uma economia à medida da humanidade, o que pressupõe a rutura com o disseminado discurso que apela à competitividade e o assumir de um discurso e uma prática de cooperação que viabilize a reconstrução de um mundo mais humano e mais solidário.

Ao longo das 245 páginas a autora apresenta a contribuição de importantes teóricos e simultaneamente expõe o seu pensamento, partilhando o seu modo de encarar a problemática que discute, apresentando de forma muito consistente os fundamentos para que na formação de quem trabalha 
ou trabalhará na área da educação social sejam assegurados os conhecimentos sobre a dimensão política de tal prática, para que a sua atuação não se resuma a mero assistencialismo social, sem a perspetiva da transformação do contexto e das realidades humanas.

Esta obra é, sem dúvida, uma excelente mais valia nas bibliotecas de investigadores/as, educadores/as, formadores/as e outros/as profissionais da área das ciências sociais, mas também nas de quem queira desenvolver o seu conhecimento sobre os diferentes aspetos deste vasto, complexo e multifacetado que é o mundo da educação social.

São 245 páginas de texto denso mas de progressiva e cativante leitura, ao longo das quais o/a leitor/a é desafiado/a a aprofundar o exposto em cada capítulo, em cada texto, através de outras leituras e pesquisas sugeridas pelos 275 títulos que regista na bibliografia referenciada e recomendada.

Nas palavras da autora, trata-se de uma obra que procura constituir-se "num ponto de partida, de índole pedagógica, para uma busca, inevitavelmente mais pessoal e autónoma, [...] visando a co-construção de saberes basilares para uma conscientização, uma auto-reflexividade crítica e uma formação política, necessária ao próprio desempenho prático profissional e de cidadania, inseparavelmente afectos aos actores locais deste campo amplo da acção social" (p. 20), na convicção de que "os obstáculos não se eternizam" (Freire, 1996: 36) ${ }^{1}$ e de que a mudança é possível.

Maria Teresa Laranjo

1 Freire, Paulo (1996), Pedagogia da autonomia - Saberes necessários à prática educativa. Editora Paz e Terra. Coleção Saberes. 